\title{
BMJ Open Delayed/back up antibiotic prescriptions: what do the public think?
}

\author{
Cliodna A M McNulty, ${ }^{1}$ Donna M Lecky, ${ }^{1}$ Meredith K D Hawking, ${ }^{1}$ Anna Quigley, ${ }^{2}$ \\ Chris C Butler $3,4,5$
}

To cite: McNulty CAM, Lecky DM, Hawking MKD, et al. Delayed/back up antibiotic prescriptions: what do the public think?. BMJ Open 2015;5:e009748. doi:10.1136/bmjopen-2015009748

- Prepublication history for this paper is available online. To view these files please visit the journal online (http://dx.doi.org/10.1136/ bmjopen-2015-009748)

Received 18 August 2015 Revised 15 October 2015 Accepted 21 October 2015

\section{(1) CrossMark}

${ }^{1}$ Primary Care Unit, Public Health England, Microbiology Department, Gloucestershire Royal Hospital, Gloucester, UK

${ }^{2}$ Ipsos MORI, Social Research Institute,

London, UK

${ }^{3}$ Nuffield Department of

Primary Care Health Sciences Oxford University, Oxford, UK

${ }^{4}$ Cardiff University, Institute of Primary Care and Public Health, Cardiff, UK

${ }^{5}$ Cwm Taf University Health Board

\section{Correspondence to}

Professor Cliodna A M

McNulty;

cliodna.mcnulty@phe.gov.uk

\section{ABSTRACT}

Objective: To describe the general public's understanding, acceptance and use of delayed antibiotics.

Design: Face to face computer-assisted survey using an Ipsos MORI Capibus survey.

Setting: Randomly selected households in England using multistage sampling.

Respondents: A representative sample of 1625 adults aged over 15 years and recruited from household visits in England, using age and gender quotas for each area. Data collection and analysis: The survey was undertaken in January 2014. Weights based on gender, age, ethnicity, working status, social grade, housing tenure and Government Office Region corrected for selection biases, so that results are broadly representative of the population.

Main outcomes measures: Proportion of respondents; understanding the meaning of the term delayed antibiotic prescription and how the strategy is used in general practice; in favour of, or opposed to clinicians offering them a delayed antibiotic; reporting receipt, use and acceptability of delayed antibiotic prescriptions in the past year.

Results: $17 \%$ reported fully understanding the meaning of delayed antibiotic prescription and strategy use in general practice; $72 \%$ were unaware of the term or strategy; $36-39 \%$ were in favour of, and $28-30 \%$ opposed to clinicians offering them a delayed antibiotic for throat, urine, ear or chest infections. Half of those who were fully aware of the term and practice were in favour of delayed antibiotics. Women, and older respondents, were more strongly opposed to delayed prescribing. Only $4 \%$ of all respondents, and $15 \%$ of those prescribed an antibiotic, reported being offered a delayed antibiotic in the last year.

Conclusions: Wider understanding and acceptance of delayed prescribing may facilitate increased uptake. Further research is needed to determine why groups are so strongly in favour or opposed to delayed prescribing.

\section{INTRODUCTION}

Many organisations, including the WHO, have published action plans to address antimicrobial resistance (AMR). ${ }^{1}{ }^{2}$ As AMR is related to antimicrobial use, ${ }^{3}$ containment

\section{Strengths and limitations of this study}

- This is the first survey of the general public regarding their opinions about delayed antibiotics.

- The results reflect the public's opinions, as our population is likely to be typical as it is a representative sample and the percentage who received an antibiotic $(34 \%)$, is similar to previous England surveys.

- The meaning of the term delayed antibiotics was explained fully to respondents immediately before asking the survey questions, this could have increased the number of respondents who responded that they fully understood.

- Since only $4 \%$ reported being offered a delayed antibiotic script, the questions asked only of this group of patients should be interpreted with caution due to small numbers.

- We did not explore why respondents were in favour or opposed to delayed prescribing - this will require further research.

strategies usually include goals to (1) conserve and steward the effectiveness of existing antimicrobials, and (2) improve the knowledge and understanding of how antibiotic use relates to AMR. Delayed (or 'back-up') antibiotic prescriptions, in which a prescription is issued by a clinician for a patient to collect or use at a later date, if they feel no better or feel worse after several days, have been used successfully to reduce antibiotic prescribing in primary care for respiratory, ${ }^{45}$ urinary $^{5}$ and conjunctival infections. ${ }^{6}$ As delayed antibiotics can be a successful stewardship strategy, their use is now encouraged in UK guidance on the management of respiratory tract infection (RTI) ${ }^{7}$ and urinary tract infection (UTI). ${ }^{8} \mathrm{~A}$ delayed antibiotic prescribing strategy reduces antibiotic use compared to immediate antibiotics, is not associated with increased risk of complications, ${ }^{9}$ may be the least costly for treating upper RTIs, ${ }^{10}$ and reduces future expectations for antibiotics. ${ }^{11}$ A Cochrane review on delayed antibiotics found that patient 
satisfaction was greater with immediate rather than delayed antibiotic prescribing; although delayed and no antibiotics had similar satisfaction rates, with over $80 \%$ of patients offered both strategies being satisfied. ${ }^{4}$ Satisfaction is important as it is strongly associated with how patients consider a doctor deals with their concerns. ${ }^{11}$ Although we know that patients in trials of delayed antibiotics are generally satisfied, ${ }^{5911}$ we do not know whether the general public understands what delayed prescribing is, or whether they welcome the use of this prescribing strategy more widely.

Delayed antibiotic prescribing by general practitioner (GPs) in Europe could be used more often; only 6.3\% of adults presenting in EU general practice with acute cough/lower RTI reported being offered a delayed prescription. ${ }^{12}$ However, it is difficult to determine the extent of use, as these prescriptions are not specifically identified with routinely collected prescribing data, ${ }^{3}$ and GPs do not routinely use the READ code for these prescriptions.

We therefore aimed to use a face to face questionnaire survey study to ascertain the general public's awareness of delayed antibiotics, the acceptability of delayed antibiotic prescriptions for infections, and whether they had been offered a delayed antibiotic, and if so, the indication and acceptability.

\section{METHODS}

For the questionnaire survey 24-30 January 2014, multistage sampling was used to recruit 1625 adults aged $15+$ from across England for face-to-face interviews in their own home. The interviews were computer assisted, that is, answers were entered immediately onto the computer during the interview. A market research company, Ipsos MORI, conducted the interviews as part of their weekly face to face survey that collects a wide range of information from across the country in a single week. ${ }^{13}$ The Face-to-Face Omnibus uses a controlled form of random location sampling which uses a two-stage sampling process. The initial sampling frame is a bespoke amalgamation of Output Areas (used for output from the Census in Great Britain) which are regrouped into primary sampling units taking account of their ACORN (a classification of residential neighbourhood) characteristics. A total of $170-180$ of these primary sampling units are randomly selected from the stratified groupings with probability of selection proportional to size. At the second stage, usually two adjacent output areas, made up of about 125 addresses each, are randomly selected from each primary sampling unit.

Interviewers are given age and gender, household tenure and working status quotas of respondents for each sample point. Interviewers go door-to-door and invite persons over 15 years who answer to participate, however, respondents will be excluded if the quotas are full. Households are visited at various times throughout the day and evening to allow working people to participate. Interviewers do not revisit households where no one answered the door. About one interview is completed for every three or four doors on which they knock.

The interview schedule was based on previous published questionnaires around antibiotics and delayed prescribing. ${ }^{14}$ The questions were developed collaboratively by the authors that included a GP involved in prescribing, advisors not involved in healthcare and with input from the Ipsos MORI health team who are experts in questionnaire design, and the PHE marketing team. The questionnaire was piloted with public advisors serving on the Department of Health ARHAI (Antimicrobial Resistance and HealthCare Associated Infection) Advisory Group. The questions formed part of a larger survey about antibiotic use for infections. First the interviewer explained that the next section was "about delayed (or deferred) antibiotics, in which an antibiotic prescription is usually written by a GP, nurse or dentist for use at a later date. The prescription is usually offered in one of two ways: Written at the time of diagnosis, to be taken to a pharmacy ONLY if you felt no better or felt worse after several days, or an opportunity is offered to return to the surgery to pick up an antibiotic prescription ONLY if you felt no better or felt worse after several days." Respondents were then asked about their understanding of the term, if they were in favour or opposed to delayed antibiotics for named infections and if they had been offered a delayed antibiotic in the past 12 months. Using computer-assisted personal interviewing ensures that routing of the questionnaire is followed correctly for all respondents. Only complete interviews are reported and included in the data, so any partial interviews (if participants terminated the interview) are excluded from the data.

\section{Questionnaire data analysis}

Weights provided by Ipsos MORI were used to correct for known selection biases. Ipsos MORI's Capibus uses a 'rim weighting' system which weights to the latest set of census data or mid-year estimates and National Readership Survey defined profiles for age, social grade, region and working status-within gender and additional profiles on tenure and ethnicity. The idea of rim weighting is to provide the 'best weighting', or least distorting, by using computing power to run a large number of solutions from which the best is chosen. Thus 'Rim weighting' is superior to the more common system of 'Cell weighting'. All results make use of the weights and allow for the clustering of the sample. Significance tests for differences in percentages were a variation of the Pearson $\chi^{2}$ test, which uses the frequency data from the sample to evaluate the relationship between the variables in the population.

\section{RESULTS}

A total of 1626 agreed to face to face interviews; data from 1625 completed interviews are included in the 
Table 1 Interviews achieved versus total population, both unweighted and weighted: population figures are from the census (once Scotland and Wales are excluded), and social grade are from Telmar

\begin{tabular}{|c|c|c|c|c|c|}
\hline $\begin{array}{l}\text { Population } \\
\text { parameter }\end{array}$ & $\begin{array}{l}\text { Population: } 2011 \text { census/ } \\
\text { NRS (\%) }\end{array}$ & $\begin{array}{l}\text { Unweighted numbers } \\
1625\end{array}$ & $\begin{array}{l}\text { Weighted } \\
\text { numbers }\end{array}$ & $\begin{array}{l}\text { Unweighted } \\
\text { (\%) }\end{array}$ & $\begin{array}{l}\text { Weighted } \\
(\%)\end{array}$ \\
\hline Male (a) & 49.18 & 826 & 795 & 51 & 49 \\
\hline Female (b) & 50.82 & 799 & 830 & 49 & 51 \\
\hline $15-24(\mathrm{e})$ & 15.89 & 289 & 259 & 18 & 16 \\
\hline 25-34 (f) & 16.41 & 244 & 274 & 15 & 17 \\
\hline $35-44(\mathrm{~g})$ & 17.04 & 216 & 262 & 13 & 16 \\
\hline $45-54(h)$ & 16.68 & 232 & 278 & 14 & 17 \\
\hline $55-64$ (i) & 14.14 & 251 & 221 & 15 & 14 \\
\hline $65+(j)$ & 19.85 & 393 & 331 & 24 & 20 \\
\hline$A B(a)$ & 27.60 & 363 & 437 & 22 & 27 \\
\hline C1 (b) & 27 & 535 & 445 & 33 & 27 \\
\hline C2 (c) & 21.80 & 348 & 351 & 21 & 22 \\
\hline$D E(d)$ & 23.60 & 379 & 393 & 23 & 24 \\
\hline
\end{tabular}

NRS, National Records of Scotland.

analysis. Table 1 shows how the interviewed population closely reflects the wider population on the key variables, and any differences are corrected for in the weighting.

Only $17 \%$ of respondents $(\mathrm{CI} \pm 1.8 \%)$ reported they fully understood the meaning of the term delayed antibiotic prescription and how the strategy is used in general practice, a further $5 \%$ had heard of the term but did not know exactly what it meant, $6 \%$ had heard of the practice but did not know the name for it, while $72 \%(\mathrm{CI} \pm 2.2 \%)$ were not aware of either the name or the practice (figure 1). Full awareness was significantly higher in women (22\%) compared to men (13\%, $\mathrm{p}<0.001)$; those in professional social grades ABC1 $(21 \%$ compared to $13 \%$ DE individuals, $\mathrm{p}=0.001$ ), those with higher educational attainment $(20 \%$ of those with A level or degree compared with $13 \%$ if no formal education $\mathrm{p}=0.015)$ and respondents with children $(21 \%$ compared to $15 \%$ with no children). Awareness was highest in part-time workers $(27 \%)$.

Between $36 \%$ and $40 \%$ of respondents tended to favour, or strongly favoured delayed antibiotics for each of the infections (chest, urine, ear or throat), $28-30 \%$ tended to oppose or strongly opposed this option, and about 3 in 10 neither favoured nor opposed. Women and older respondents were more likely to be opposed to delayed antibiotics; $34 \%$ of women and $36 \%$ of those aged $65+$ opposed the use of delayed antibiotics for throat infection compared to $26 \%$ men and $26 \%$ of those under 45 years $p=0.002$. These proportions were similar for each of the infections. Those 274 respondents who were aware of the term and practice of delayed antibiotics were significantly more likely than those 1181 respondents who had not heard of the term or the practice, to be in favour or strongly to GP's, nurses or dentists issuing delayed antibiotic prescriptions for chest, urine, ear or throat infections ( $49 \%$ vs $32 \%$ in favour for throat infection and $54 \%$ vs $36 \%$ in favour for chest infections) (table 2). When asked about their infections and antibiotic use in the past 12 months, 65\% (1052) respondents reported that they had an infection, 34\% (449) reported being prescribed antibiotics, $10 \%$ (172) reported asking a GP or nurse for antibiotics and $4 \%$ $(\mathrm{CI} \pm 1.2 \%, \mathrm{n}=65)$ reported that they had been offered a delayed antibiotic option (14\% of those prescribed an
Figure 1 Percentage of general public aware of the term 'delayed antibiotic' and/or the practice $(n=1625)$.

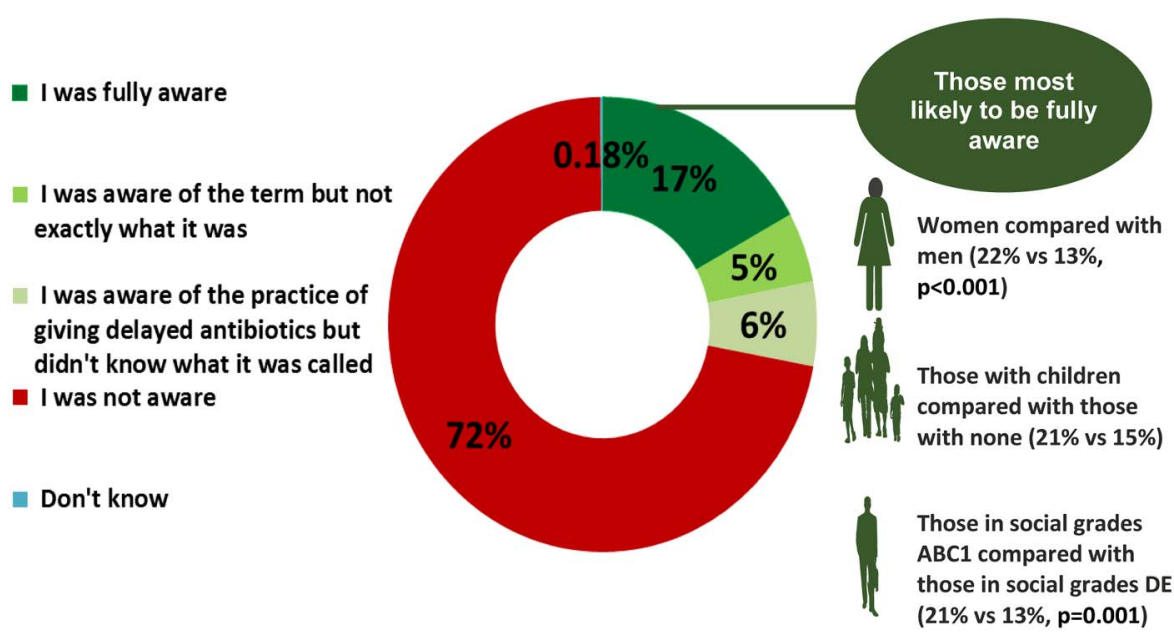



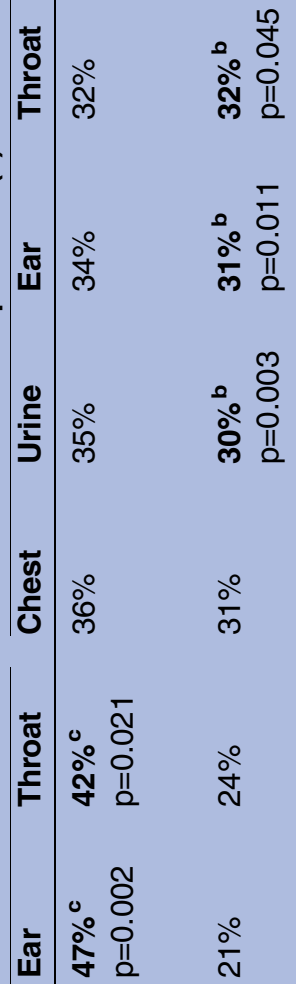

iin

$\stackrel{\circ}{\grave{N}}$

$\stackrel{\circ}{\circ}$

ڤे

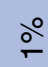

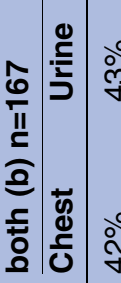

$\stackrel{\circ}{\circ}$

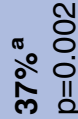

o.

움

ํํำ

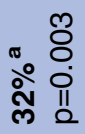

ஜ̊

$\stackrel{\circ}{\circ}$

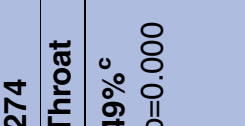

$\stackrel{\circ}{\stackrel{N}{N}}$

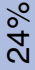

$\stackrel{\circ}{\stackrel{\circ}{N}}$
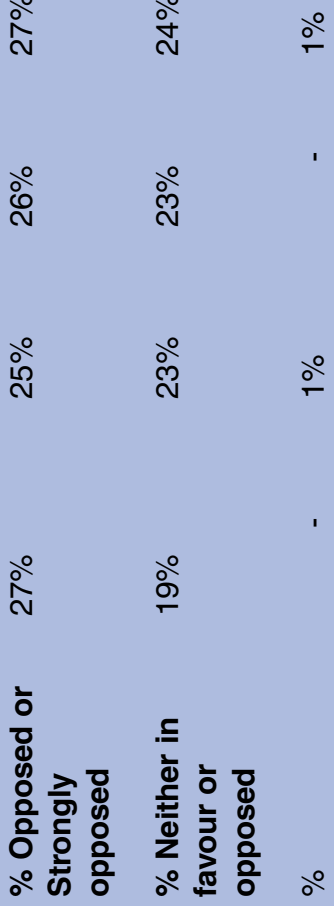

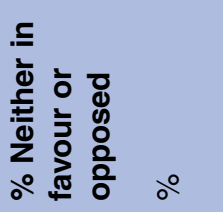

antibiotic $(\mathrm{CI} \pm 1 \%, \mathrm{n}=65)$ (figure 2$)$. Women $(5 \%, \mathrm{CI} \pm 1.5$-x, $\mathrm{n}=43 / 830)$, those with children $(7 \%, \mathrm{CI} \pm 2.3 \%, \mathrm{n}=35 / 525)$, and those with no formal education $(6 \%, \mathrm{CI} \pm 2.3 \%, \mathrm{n}=20)$ or in social grade DE $(7 \%, \mathrm{CI} \pm 2.6 \%, \mathrm{n}=26 / 393)$ were more likely to have been offered a delayed prescription (table 3). Respondents reporting RTIs in the last year were significantly more likely to report being offered a delayed antibiotic compared to the total sample; $10 \%$ who reported having a throat infection $(18 / 186, \mathrm{p}=0.016)$ or ear infection $(8 / 78, \mathrm{p}=0.016), 8 \% \quad(14 / 180, \mathrm{p}=0.014)$ reporting a chest infection, $9 \%(17 / 201, p=0.001)$ flu symptoms. Overall, 5\% (CI $\pm 1.4, \mathrm{n}=45)$ of respondents with any RTI reported being offered a delayed antibiotic in the past year. When recipients of delayed prescriptions were asked to score acceptability of the approach on a Likert scale from 1 to 10 where 10 is completely acceptable, the mean score was $7.9 ; 26 / 37$ scored 8 or more and $17 / 37$ scored 10 . Overall $60 \%(35 / 59)$ of those offered a delayed antibiotic reported collecting the antibiotic from the pharmacy.

\section{DISCUSSION}

Less than one in five respondents was fully aware of the concept of a delayed antibiotic prescription. Respondents were split between being in favour of, opposed to, or neither in favour or opposed to clinicians offering them a delayed antibiotic prescription should they have an infection, suggesting opportunity to increase knowledge and use of this prescribing strategy. However, increased awareness was associated with some increased support for the strategy, as half of those fully aware of the strategy were in favour compared to a third who were not aware. Women were more aware of delayed antibiotics, but also more strongly opposed to the option. Older respondents, who tend to have greater comorbidity, were also more opposed to the delayed antibiotic option. Only $4 \%$ of all respondents and $15 \%$ of those prescribed an antibiotic reported being offered a delayed antibiotic.

\section{Strengths and limitations}

This is the first survey of the general public regarding their opinions about delayed antibiotics; as it is a representative sample, it is likely to reflect the public's opinions. Our population is likely to be typical, as the percentage who received an antibiotic $34 \%$, is similar to a previous survey in England in which $32.5 \%$ reported being prescribed antibiotics in the past year. ${ }^{14}$ The meaning of the term delayed antibiotics was explained fully to respondents immediately before asking "Before today, to what extent were you aware of what a delayed antibiotic was?"; this could have increased the number of respondents who responded that they fully understood. However, we believe that by giving the full explanation, the numbers of respondents reporting being offered a delayed antibiotic is probably more accurate than in a previous survey in 2011 done by the same 


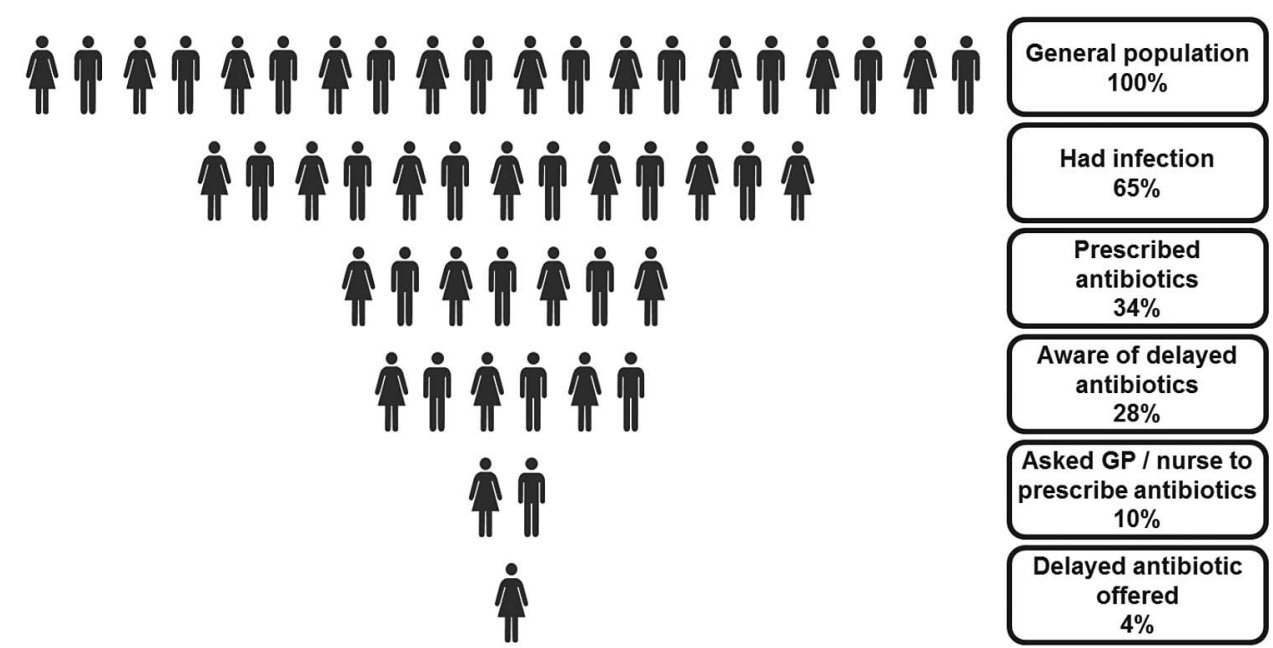

Figure 2 Percentage of the general public in the last year who reported: having an infection, being prescribed antibiotics, being aware of or practice of delayed antibiotics, asking for antibiotics, being offered delayed antibiotics $(n=1625)$. GP, general practitioner.

group in which the full explanation was not given, and many more respondents $(14.2 \%)$ reported being offered a delayed antibiotic prescription. ${ }^{14}$ Since only $4 \%$ reported being offered a delayed antibiotic script, the questions asked only of this group of patients should be interpreted with caution due to small numbers. We did not explore why respondents were in favour or opposed to delayed prescribing-this will require further research.

\section{Comparison with existing literature}

Previous work in this area has generally been with GPs or patients involved in treatment trials of evaluation of delayed antibiotics for infections. Norwegian GPs who were involved in an educational intervention to improve antibiotic prescribing were interviewed and supported the use of delayed antibiotics for mild RTIs, especially to avoid out-of hours visits and for patients who were pressurising them to prescribe. However, they felt that they could only use this delayed option in 'knowledgeable' patients who understood how to use it. ${ }^{15}$ This opinion was also voiced by patients and GPs in a New Zealand study; patients reported that they thought the concept of delayed prescribing may be confusing for less-educated people. ${ }^{16}$ Certainly in our study, full awareness of the concept of delayed prescribing was greater in those with higher educational attainment, but although our data suggest that respondents with no formal education are more likely to be offered a delayed prescription this did not reach significance because of small numbers (no formal education 6\% and social grades DE 7\% compared to ABC1 3\%, $\mathrm{p}=0.071$ ).

The GPs in the New Zealand study also reported that they did not use delayed antibiotics in those patients that they consider at higher risk of more severe or complicated infections-this included the elderly. ${ }^{16}$ In our sample of the general public, those over 45 years were more likely to be opposed or strongly opposed to the use of delayed antibiotics than the younger age groups. This indicates that GPs might need to use more explanation in this older age group. Thresholds for consulting may differ by age, with older people possibly attending for more severe infections or only when they feel that antibiotics are really necessary.

It was interesting that a third of our respondents were opposed to the use of delayed antibiotics, and only two

Table 3 Weighted number and percentage of respondents offered delayed prescription of any type in the last year ( $n=1625)$ of each social, grade, gender and if they have children under 16 years or have had an infection in the previous year

\begin{tabular}{|c|c|c|c|c|c|c|c|c|c|c|}
\hline & & \multirow[b]{2}{*}{ Total } & \multicolumn{4}{|c|}{ Social grade } & \multicolumn{2}{|c|}{ Gender } & \multicolumn{2}{|c|}{$\begin{array}{l}\text { Have children } \\
<16 \text { years }\end{array}$} \\
\hline & & & $\begin{array}{l}\mathrm{AB} \\
\text { (a) }\end{array}$ & $\begin{array}{l}\text { C1 } \\
\text { (b) }\end{array}$ & $\begin{array}{l}\text { C2 } \\
\text { (c) }\end{array}$ & $\begin{array}{l}\text { DE } \\
\text { (d) }\end{array}$ & $\begin{array}{l}\text { Male } \\
\text { (e) }\end{array}$ & $\begin{array}{l}\text { Female } \\
\text { (f) }\end{array}$ & $\begin{array}{l}\text { Any } \\
\text { (g) }\end{array}$ & $\begin{array}{l}\text { None }<16 \\
\text { (h) }\end{array}$ \\
\hline Unweighted base & $\mathrm{n}$ & 1625 & 363 & 535 & 348 & 379 & 826 & 799 & 470 & 1155 \\
\hline Weighted base & $\mathrm{n}$ & 1625 & 437 & 445 & 351 & 393 & 795 & 830 & 525 & 1100 \\
\hline Offered delayed antibiotic in past year & $\mathrm{n}$ & 65 & 14 & 15 & 11 & 26 & 22 & 43 & 35 & 29 \\
\hline p Value & $\%$ & $4 \%$ & $3 \%$ & $3 \%$ & $3 \%$ & $\begin{array}{l}7 \% \%^{*} a b c \\
{ }^{*} 0.006\end{array}$ & $3 \%$ & $\begin{array}{l}5 \% \%^{*} e \\
{ }^{*} 0.017\end{array}$ & $\begin{array}{l}7 \% * h \\
{ }^{*} 0.0001\end{array}$ & $3 \%$ \\
\hline
\end{tabular}


in five in favour. A qualitative study has shown that use of delayed prescribing is not widespread or taken up uniformly in all parts of the country and does not have full or universal support among clinicians, ${ }^{17}$ so it is perhaps not surprising that the majority of our sample of the general public do not have an understanding of what this option is. This range of opinion and practice among clinicians has also been found in qualitative interviews with patients in trials of delayed prescribing; some patients and GPs report delayed prescribing strengthened the patient-clinician relationship, but others felt it could damage relationships, as patients may perceive delayed prescribing as an indication of clinician incompetence or a way of saving money. ${ }^{16}{ }^{17}$ Patient satisfaction is high in trials evaluating delayed prescriptions, ${ }^{4}{ }^{18}$ but this may not reflect the situation when the strategy is used in the general population in routine care where the patient-clinician interaction is likely to be under $10 \mathrm{~min}$. In this current survey, the small number of patients who were actually offered a delayed antibiotic reported being highly satisfied. This suggests that opposition to delayed antibiotics can probably be overcome with adequate explanation about self-care. Indeed, GPs have reported that delayed prescribing gave an opportunity to practice more patient-centred medicine that included educating patients to take more responsibility for their own health. ${ }^{16}{ }^{17}$ However, this was not mentioned by the patients themselves interviewed in one study. ${ }^{16}$ A leaflet to facilitate the discussion around issuing a delayed/back-up antibiotic prescription, ${ }^{19}$ has been evaluated in face to face interviews in England. ${ }^{20}$ Before any explanation of the term was provided, $74 \%$ (26 of 35) of respondents had not heard of a delayed prescriptions and did not understand when it would be used. ${ }^{20}$ The term 'back up' prescription was preferred to 'delayed' as this would signify 'just in case' antibiotics rather than a delay for treatment. ${ }^{20}$ Using the term 'back-up antibiotic' may increase the public understanding and acceptance of this form of antibiotic prescription. $^{20}$ The TARGET leaflet ${ }^{19}{ }^{20}$ addresses the patient-centred approach mentioned in the qualitative work with GPs in New Zealand, ${ }^{14}$ and also indicates when patients need to pick up the prescription. ${ }^{19}$ The need for adequate information was also highlighted by GPs involved using delayed antibiotics for RTI ${ }^{13}$ and by women in studies of delayed antibiotics for UTI. ${ }^{21}{ }^{22}$ In these studies, most women were happy with the delayed antibiotic strategy for UTI as they wanted to avoid unnecessary antibiotics, but some women reported negative experiences in that they felt that they were not listened to or the severity of symptoms were not appreciated by their GP. $^{21}$ The need for clear advice during the consultation was also stressed in a 2014 randomised controlled trial (RCT) of prescribing strategies for RTI. ${ }^{5}$ Lower levels of trust in a doctor's advice are associated with lower adherence to their advice. ${ }^{23}$ Other qualitative work has found the successful use of the strategy is highly dependent on trust in a doctor's offer. We found that a third of the general public are currently not in favour of delayed/back-up antibiotic prescribing, so clinicians should consider trust issues, and consider whether patients are happy with the approach before it is pursued.

\section{Implications for research and/or practice}

Half of patients who understand the term are in favour of being offered delayed antibiotics, indicating that there is an opportunity to increase their use in this group. Our research also indicates that there is an opportunity to further increase understanding of, acceptance and use of delayed antibiotic prescribing among the general public who do not understand the term or practice. As younger age groups are more in favour of this strategy, delayed antibiotics may be easiest to introduce more widely in this group who are the sector of the population (with the elderly) who report using most antibiotics. ${ }^{24} 25$ In older groups, adequate explanation of the term and its advantages will be needed to overcome the possible opposition voiced by these groups. Using the terms such as 'back-up antibiotics' as suggested by Bunten $e t a l^{20}$ may help to increase patients' understanding and acceptance. Normalisation of delayed/back-up antibiotic prescribing is needed to increase wide acceptance and knowledge of the practice. Further research is needed to determine why groups are so strongly in favour or opposed and how it should be explained.

Acknowledgements The authors would like to thank Christine Roberts at PHE marketing and the staff at Ipsos MORI including Daniel Marshall, Sarah Shepherd and David Jeans for their advice with question format and data analysis, and the public who answered the questionnaire.

Contributors CAMM conceived and led the study. CAMM, CCB, DML, MKDH and Ipsos MORI contributed to the design of the questionnaire survey. Ipsos MORI carried out the questionnaire survey and data processing. All authors contributed to drafting and have seen and approved the final version of the manuscript.

Funding This study was funded internally by Public Health England.

Competing interests All authors have completed the Unified Competing Interests Form at http://www.icmje.org/coi_disclosure.pdf. CAMM leads the development and writes evidence-based antibiotic guidance for primary care and leads the RCGP TARGET antibiotic toolkit development including a patient leaflet encouraging delayed/back-up prescribing. She is a member of ARHAI. Any payment for speaking at conferences goes to a research trust fund. CCB has received grants from several publicly funded research granted bodies on the public understanding of antibiotics use and led trails to improve the quality of antibiotic use. He has received unconditional support from Alere in the form of a loan of point of care testing devices to support a trail of the management of acute exacerbations of COPD, and has received honoraria from Alere.

Ethics approval The Ipsos MORI surveys and interviews were undertaken outside the NHS setting and therefore did not need NHS ethical approval. Consent to take part in the survey was by verbal agreement to participate with completion of the questionnaire considered as indicating consent; respondents were not given any financial incentive. Respondents were able to refuse to participate in the questionnaire at any stage in the process. All data was processed in accordance with the Data Protection Act 1998. 
Provenance and peer review Not commissioned; externally peer reviewed.

Data sharing statement No additional data are available.

Open Access This is an Open Access article distributed in accordance with the Creative Commons Attribution Non Commercial (CC BY-NC 4.0) license, which permits others to distribute, remix, adapt, build upon this work noncommercially, and license their derivative works on different terms, provided the original work is properly cited and the use is non-commercial. See: http:// creativecommons.org/licenses/by-nc/4.0/

\section{REFERENCES}

1. World Health Organisation. Combating antimicrobial resistance, including antibiotic resistance. Document EB134.R13. 2014. http:// apps.who.int/gb/ebwha/pdf_files/EB134/B134_R13-en.pdf (accessed 10 Apr 2015)

2. Department of Health. UK Five Year Antimicrobial Resistance Strategy 2013-2018. https://www.gov.uk/government/uploads/ system/uploads/attachment_data/file/244058/20130902_UK_5_year_ AMR_strategy.pdf (accessed 10 Apr 2015).

3. Public Health England. The English Surveillance Programme for Antimicrobial Utilisation and Resistance Report. 2014. https://www. gov.uk/government/uploads/system/uploads/attachment_data/file/ 362374/ESPAUR Report 2014 3 3 .pdf

4. Spurling GK, Del Mar CB, Dooley L, et al. Delayed antibiotics for respiratory infections. Cochrane Database Syst Rev 2013;4: CD004417.

5. Little P, Moore MV, Turner S, et al. Effectiveness of five different approaches in management of urinary tract infection: randomised controlled trial. BMJ 2010;340:c199.

6. Everitt HA, Little PS, Smith PW. A randomised controlled trial of management strategies for acute infective conjunctivitis in general practice. BMJ 2006;333:321.

7. NICE. Clinical Guidance 69: Respiratory tract infections-antibiotic prescribing: Prescribing for antibiotics for self-limiting respiratory tract infections in adults and children in primary care. 2008. http://www. nice.org.uk/guidance/cg69/resources/guidance-respiratory-tractinfections-antibiotic-prescribing-pdf (accessed 10 Apr 2015).

8. Public Health England. Management of infection guidance for primary care for consultation and local adaptation. 2014. https:// www.gov.uk/government/uploads/system/uploads/attachment_data/ file/377509/PHE_Primary_Care_guidance_14_11_14.pdf (accessed 10 Apr 2015)

9. Little P, Stuart B, Hobbs FD, et al. DESCARTE investigators. Predictors of suppurative complications for acute sore throat in primary care: prospective clinical cohort study. BMJ 2013;347:f6867.
10. Coco AS. Cost-effectiveness analysis of treatment options for acute otitis media. Ann Fam Med 2007;5:29-38.

11. Little $\mathrm{P}$, Williamson I, Warner $\mathrm{G}$, et al. Open randomised trial of prescribing strategies in managing sore throat. $B M J$ 1997;314:722-7.

12. Francis NA, Gillespie D, Nuttall J, et al. Delayed antibiotic prescribing and associated antibiotic consumption in adults with acute cough. Br J Gen Pract 2013;63:12.

13. Ipsos MORI face to face Omnibus Survey (Capibus). https://www. ipsos-mori.com/researchareas/omnibusservices/capibus.aspx

14. McNulty CAM, Nichols T, French DP, et al. Expectations for consultations and antibiotics for respiratory tract infection in primary care: the RTI clinical iceberg. Br J Gen Pract July 2013;63:e429-36.

15. Høye S, Gjelstad S, Lindbaek M. Effects on antibiotic dispensing rates of interventions to promote delayed prescribing for respiratory tract infections in primary care. Br J Gen Pract 2013;63:e777-86.

16. Arroll B, Goodyear-Smith F, Thomas DR, et al. Delayed antibiotic prescriptions: What are the experiences and attitudes of physicians and patients? J Fam Pract 2002;51:954-9.

17. Peters $\mathrm{S}$, Rowbotham $\mathrm{S}$, Chisholm A, et al. Managing self-limiting respiratory tract infections: a qualitative study of the usefulness of the delayed prescribing strategy. Br J Gen Pract 2011;61: e579-89.

18. Dowell J, Pitkethly M, Bain J, et al. A randomised controlled trial of delayed antibiotic prescribing as a strategy for managing uncomplicated respiratory tract infection in primary care. $\mathrm{Br} J$ Gen Pract 2001;51:200-5.

19. Public Health England \& Royal College of General Practitioners. TARGET antibiotics toolkit. http://www.rcgp.org.uk/targetantibiotics (accessed 10 Apr 2015).

20. Bunten AK, Hawking MKD, McNulty CAM. Patient information can improve appropriate antibiotic prescribing. Nurs Pract 2015;82:61-3.

21. Leydon GM, Turner S, Smith H, et al. UTIS team. Women's views about management and cause of urinary tract infection: qualitative interview study. BMJ. 2010;340:c279.

22. Willems SJC, van den Broek D'Obrenan J, Numans ME, et al. Cystitis: antibiotic prescribing, consultation, attitudes and opinions. Fam Pract 2014;31:149-55.

23. Thom DH, Kravitza RL, Bellb RA, et al. Patient trust in the physician: relationship to patient requests. Fam Pract 2002;19:476-83.

24. European Commission. Special Eurobarometer 407: Antimicrobial Resistance. 2013. http://ec.europa.eu/public_opinion/archives/ebs/ ebs_407_en.pdf (accessed 10 Apr 2015).

25. McNulty CAM, Boyle P, Nichols T, et al. The public's attitudes to and compliance with antibiotics. J Antimicrob Chemother 2007;60 (Suppl 1):i63-8. 